\title{
Una aproximación teórica a las olas del feminismo: la cuarta ola
}

\author{
A theoretical approach to the waves of feminism: \\ the fourth wave
}

\author{
NANi AgUILAR BARRIGA* \\ Doctoranda \\ Facultad de Derecho de Málaga
}

Recibido: 05/07/2019

Aceptado: $12 / 02 / 2020$

doi: https://doi.org/10.20318/femeris.2020.5387

\begin{abstract}
Resumen. Este estudio tiene por objeto dar visibilidad a las primeras voces feministas que, en un primer momento, de forma individual a través de sus obras y en un segundo momento, de forma colectiva con el surgimiento del movimiento feminista, lucharon y luchan por una sociedad donde el hombre y la mujer se encuentren en una situación de equilibrio; de misma valoración y consideración y dispongan de los mismos derechos y oportunidades. De esta manera, el presente análisis se adentrará en las conocidas como Olas del feminismo, que pondrán de manifiesto, cómo las mujeres partiendo de una situación de discriminación e invisibilización, mantenida y perpetuada a través de la Historia por los roles de género y el patriarcado, en todos los ámbitos de la sociedad; social, político, económico, cultural, civil, religioso y privado, fueron dando pasos hacia la igualdad. El estudio finalizará incidiendo de manera especial en las numerosas y masivas manifestaciones de mujeres y hombres feministas en todas las partes del planeta e, indicadores, que hacen posible hablar de la existencia de la Cuarta Ola feminista y de sus objetivos: La lucha por la eliminación de todas las formas de violencia hacia la mujer por el simple hecho de ser mujer, incluida la violencia sexual y prostitución y, la consecución de la paridad real entre el hombre y la mujer en todos los ámbitos.

Palabras clave: Olas del feminismo, Primera Ola del feminismo, Segunda Ola del feminismo, Tercera Ola del feminismo, Cuarta Ola del feminismo, igualdad real.
\end{abstract}

Abstract. This study aims to give visibility to early feminist voices at first, individually through their works and in a second moment, collectively with the rise of the feminist movement, fought and are fighting for a society where man and woman are in a state of equilibrium; the same valuation and consideration and which have the same rights and opportunities. Thus, this analysis will delve into what are known as waves of feminism, which will emerge, how women from a situation of discrimination and invisibility, maintained and perpetuated throughout history by gender roles and patriarchy in all spheres of society; social, political, economic,

*nani_aguilar@hotmail.es 
cultural, civil, religious and private, they were taking steps toward equality. The study will be completed focusing especially in the many mass demonstrations of women and feminist men in all parts of the world and, indicators that make it possible to speak of the existence of the Fourth Wave feminism and its objectives: The struggle for elimination of all forms of violence against women simply because they are women, including sexual violence and prostitution and parity between men and women in all areas.

Keywords: Waves of feminism, First Wave of feminism, Second-Wave feminism, ThirdWave feminism, Fourth-Wave of feminism, real equality.

\section{Visibilizando a las primeras voces feministas}

"Los roles masculinos y femeninos no están fijados biológicamente, sino que son construidos socialmente" JUDITH BUTLER

El movimiento colectivo feminista de transformación de la sociedad, de la realidad, se articula como un proceso, como una sucesión de etapas, las llamadas Olas del feminismo, iniciado, por esas primeras voces feministas que, en un primer momento, de forma individual, visualizaron un mundo libre de violencia, libre de desigualdades que se originaban por el simple hecho de nacer mujer.

A modo introductorio, previamente a proceder a realizar un análisis detallado de las diferentes etapas en la lucha por la igualdad entre el hombre y la mujer; las Olas del feminismo, hasta llegar a mostrar la situación de la mujer actualmente en nuestras sociedades del siglo XXI, hay que remitirse a las siguientes palabras esclarecedoras:

La violencia contra las mujeres, aún en un universo de violencia, presenta claves específicas, es decir, formas específicas de legitimación, basadas no en su condición de personas sino de mujeres. Esta legitimación procede de la conceptualización de las mujeres como inferiores y como propiedades de los varones, a los que deben respeto y obediencia y encuentra un refuerzo crucial en los discursos religiosos, entonces, si unimos el discurso tradicional de la religión, con el discurso costumbrista-popular, (...) con el discurso radical de Rousseau y el discurso trasgresor de Nietzsche, observaremos que desde todos los lados del abanico ideológico ha estado y está justificado la violencia ${ }^{1}$.

El feminismo, hace memoria, la feminista Ana de Miguel:

Como teoría y como movimiento social ha recorrido un largo camino repleto de dificultades hasta llegar a redefinir la violencia contra las mujeres como un problema social y político (...) Una de las tareas decisivas del feminismo ha consistido en descubrir y desarticular las múltiples y a veces contrapuestas formas de legitimación ancladas en nuestra sociedad ${ }^{2}$.

\footnotetext{
${ }^{1}$ De Miguel, Ana. (2005). La construcción de un marco feminista de interpretación: La violencia de género. Cuadernos de Trabajo Social. Vol. 18, p. 235.

${ }^{2}$ Ibidem op. cit. p. 232.
} 
Cuando se define el feminismo como movimiento social, debe entenderse por movimiento social como una forma de acción colectiva, "cuya existencia es en sí misma una forma de percibir la realidad, ya que vuelve controvertido un aspecto de la realidad que fue previamente aceptado como normativo"3 ${ }^{3}$ con capacidad para producir nuevas normas en la sociedad.

El sociólogo cultural americano Joseph Gusfield, cuando analiza los movimientos sociales, puntualiza: "La misma existencia de un movimiento social (...) presenta un aspecto de la vida social que ahora está sometido a discusión pública, aunque anteriormente hubiera sido aceptado como la norma. Donde la elección y la discusión estaban ausentes, están ahora presentes las alternativas"4.

Retoma la autora Ana de Miguel las palabras de la filósofa feminista Celia Amorós cuando reflexiona en torno a la teoría feminista:

Teoría crítica que irracionaliza la visión establecida de la realidad y, nos recuerdan la raíz etimológica de teoría, que en griego significa ver, para subrayar el que es el fin de toda teoría: posibilitar una nueva visión, una nueva interpretación de la realidad, su resignificación (...) La teoría, pues, nos permite ver cosas que sin ellas no vemos, el acceso al feminismo supone la adquisición de un nuevo marco de referencia, unas gafas que muestran a menudo una realidad ciertamente distinta de la que percibe la mayor parte de la gente ${ }^{5}$.

La etapa histórica del Renacimiento, movimiento cultural que surge en Europa occidental en los siglos XV y XVI, supuso el momento histórico en el que se introdujo la semilla de la igualdad gracias a las primeras mujeres que, en sus obras, empiezan a cuestionarse los inmutables deberes, posición subordinada e, invisibilidad, asignados por la cultura y la sociedad a la mujer.

Entre las primeras voces que se fueron alzando para hacer constar la injusticia, desigualdad, discriminación y desequilibrio, al que estaban sometidas y de que eran objeto las mujeres, se encuentra la voz de la primera escritora reconocida Christine de Pizán (1365-1431) que, en 1405, escribió su obra La ciudad de las Damas.

En la obra La Ciudad de las Damas, Christine de Pizán, reflexionó sobre cómo sería una ciudad donde no existieran las guerras fomentadas por el hombre ${ }^{6}$, cuando se planteaba: "Me preguntaba cuáles podrían ser las razones que llevan a tantos hombres, clérigos y laicos a vitupear a las mujeres, criticándolas, bien de palabra, bien en escritos y tratados"7.

La autora francesa Christine de Pizán, analiza y visibiliza, la feminista española Nuria Varela, "decide fiarse más de su experiencia que de los escritos masculinos y con esa

\footnotetext{
${ }^{3}$ Laraña, Enrique., Gusfield, Joseph. (Eds.), (1994). Los nuevos movimientos sociales. De la ideología a la identidad. Madrid: Centro Investigaciones Sociológicas (CIS), p. 68.

${ }^{4}$ Ibidem op. cit. p. 106.

${ }^{5}$ De Miguel, Ana. (2005). La construcción de un marco feminista de interpretación: La violencia de género. Cuadernos de Trabajo Social. Vol. 18, p. 234.

${ }^{6}$ Varela, Nuria. (2018). Feminismo para principiantes. Barcelona: Penguin Random House Grupo Editorial, S. A. U., p. 24.

${ }^{7}$ De Pizán, Christine. La ciudad de las Damas, traducción de Marie-José Lemarchand, Siruela, Madrid, 2.a ed, 2001, pág. 64.
} 
idea escribe La ciudad de las damas (...) Se adjudicó a Boccaccio hasta 1786, cuando otra mujer, Louise de Kéralio, recuperó para Christine de Pizán la autoría del libro”8.

Las ideas que Christine de Pizán desarrolla de su Ciudad Nueva9 ${ }^{9}$, se inspiran en una obra del escritor italiano Giovanni Boccaccio, en concreto, en su obra Claris Mulieribus. La protagonista de la obra La ciudad de las Damas es una mujer viuda que como Christine de Pizán se enfrenta a dificultades económicas para poder conservar sus posesiones cuando se encuentra en la viudez. La escritora De Pizán, "tiene sus primeros contactos con el derecho (...) en los pleitos que entabló como viuda para defenderse del expolio de sus bienes" ${ }^{10}$.

Christine de Pizán, refleja de forma, muy detallada, los abusos de poder de los hombres sobre las mujeres:

La Ciudad de las Damas como baluarte para resistir el asedio de la violencia masculina, escrita o gestual, la metáfora de la mujer que se encierra para liberarse vuelve a menudo a la obra de Cristina de Pizán como un elogio de mujeres independientes, que rompieron vínculos familiares y escaparon de la autoridad paterna y/o marital para recluirse en abadías; algo que, por supuesto, tenemos que situar en la época recordando que aquélla solía ser la única salida para las mujeres que tenían pretensiones intelectuales o aspiraban a recibir estudios, más simple aún, querían llegar a ser ellas mismas ${ }^{11}$.

La construcción de la Ciudad Perfecta ${ }^{12}$ de Christine de Pizán, remite, asimismo, a la Ciudad de Dios de San Agustín, pero, a diferencia de ésta, La Cité des Dames permite la existencia de mujeres ejemplares y célebres: "Queda terminada la construcción de nuestra Ciudad que os acogerá a todas. Vosotras que os apreciáis de virtud, dignidad y fama, seréis bien acogidas en una Ciudad levantada y edificada para todas las mujeres de mérito, las de ayer, hoy y mañana"13.

La siguiente voz "pionera de un feminismo incipiente" fue Marie de Gournay (15651645), autora de las obras Igualdad entre los hombres y las mujeres y Agravio de damas, donde "rechaza la desigualdad natural de los sexos apostando por la educación como medio reparador"14.

María de Zayas (1590-1661) fue, asimismo, una de las primeras escritoras europeas y, precursora del feminismo español que, a través de su obra, denunció la opresión de que

\footnotetext{
${ }^{8}$ Varela, Nuria. (2018). Feminismo para principiantes. Barcelona: Penguin Random House Grupo Editorial, S. A. U., p. 25.

${ }^{9}$ De Pizán, Christine. La ciudad de las Damas, traducción de Marie-José Lemarchand, Siruela, Madrid, 2.a ed, 2001, p. 272.

${ }^{10}$ Ibidem op. cit. p. 22.

${ }^{11}$ De Pizán, Christine. La ciudad de las Damas, traducción de Marie-José Lemarchand, Siruela, Madrid, 2.a ed, 2001, p. 48.

${ }^{12}$ Fernández, Etelvina. (2007). El conocimiento del pasado a través del Libro de la Ciudad de las Damas de Christine de Pizán. Anuario del Departamento de Historia y Teoría del Arte (U.A.M.). Vol. XIX. Instituto de Estudios Medievales. Universidad de León. Recuperado de https://revistas.uam.es/anuario/article/view/2400.

${ }^{13}$ Ibidem op. cit. p. 272.

${ }^{14}$ Rodriguez, Rosa María. (Ed.), (1997). Mujeres en la historia del pensamiento. Valencia: Anthropos. p. 11.
} 
fue objeto la mujer. Fue "una de las poquísimas mujeres escritoras (...) que precisamente tanto luchó por la incorporación a la mujer al mundo de los estudios y la cultura"15.

La razón de ser de la escritura de María Zayas, "es (...) la de enseñar a las mujeres. Ésta relaciona íntimamente didactismo y feminismo que constituyen la piedra angular de su visión del mundo (...) La veracidad de su historias y personajes se entiende como el deseo de dar vida a sus novelas con el objeto de relacionarlo con la vida de sus lectoras que es lo que quiere contribuir a transformar"16. Lo que la escritora "exige para las mujeres es el derecho a la cultura de forma que puedan desarrollar su inteligencia y competir con el hombre en el campo del saber, el derecho a la elección del marido que le permita expresar sus sentimientos afectivos y, por último, el derecho a la libertad de acción"17. Sus argumentos "parten de la igualdad en esencia entre hombre y mujer, a los que separa únicamente, el estudio y la dedicación"18.

Reflexiona, así, María de Zayas, en su primera obra Tres novelas amorosas y tres desengaños amorosos: "Esta virtuosa osadía de sacar a la luz mis borrones, siendo mujer (...) porque de esta materia de que nos componemos los hombres y las mujeres, ya sea una trabazón de fuego y barro, o ya una masa de espíritus y terrones, no tiene más nobleza en ellos que en nosotras, si es una misma la sangre, los sentidos, las potencias y los órganos por donde se obra sus efectos son uno mismo, la misma alma que ellos, porque las almas ni son hombre ni son mujeres; ¿Qué razón hay para que ellos sean sabios y presuman que nosotras no podemos serlo? Esto no tiene más respuesta que su (...) tiranía en encerrarnos, y no darnos maestros; y así, la verdadera razón de no ser las mujeres doctas no es defectos del caudal, sino falta de aplicación porque si (...) nos dieran libros y preceptores fuéramos tan aptas para los puestos y para las cátedras como los hombres"19.

En la etapa histórica del Renacimiento no se habla todavía de la palabra feminismo. Las quejas y denuncias de las primeras mujeres contra la opresión que sufrían no se consideran feministas puesto que "no cuestionaban el origen de esa subordinación femenina. Tampoco se había articulado siquiera, un pensamiento destinado a recuperar los derechos arrebatados a las mujeres" ${ }^{20}$. De toda esta disputa, la historia "apenas ha respetado los textos femeninos o aquellos que defendían a las mujeres, pero sí ha llegado hasta nuestros días la reacción a ellos, como señala Ana de Miguel, con obras tan (...) misóginas como Las mujeres sabias de Molière o La culta latiniparla de Quevedo"21.

\footnotetext{
${ }^{15}$ De Zayas, María. (1989). Tres novelas amorosas y tres desengaños amorosos. Madrid: Editorial Castalia, S.A., p. 12.

${ }^{16}$ Ibidem op. cit. pp. 33- 34.

${ }^{17}$ De Zayas, María. (1989). Tres novelas amorosas y tres desengaños amorosos. Madrid: Editorial Castalia, S.A., pp. 35-36.

${ }^{18}$ Ibidem op. cit. p. 36.

${ }^{19}$ Ibidem op. cit. pp. 47-48.

${ }^{20}$ Varela, Nuria. (26/01/2013). Christine de Pizán y “La ciudad de las damas”. Recuperado de http://nuriavarela. com/christine-de-pizan-y-la-ciudad-de-las-damas/.

${ }^{21}$ Varela, Nuria. (2018). Feminismo para principiantes. Barcelona: Penguin Random House Grupo Editorial, S. A. U., p. 26.
} 


\section{Primera Ola del feminismo (siglos XVIII - XIX)}

"El hombre hace, la mujer es" CHARLOTTE BRONTË

El siguiente autor que por la importancia de sus contribuciones en la lucha por la igualdad entre mujeres y hombres es necesario destacar es el filósofo y pensador francés, precursor feminista, François Poulain de la Barre, quien en la horquilla cronológica de 1673 y 1675, publica tres obras que se pueden calificar de obras feministas: De la igualdad de los sexos, La educación de las damas para la conducta del espíritu en las ciencias y las costumbres y La excelencia de los hombres contra la igualdad de los sexos ${ }^{22}$.

En palabras de la feminista española Celia Amorós, en la obra De la igualdad de los sexos, François Poulain de la Barre, "trata de derivar, a favor de los derechos de las mujeres, las implicaciones de las críticas cartesianas del prejuicio, la tradición y el argumento de autoridad, así como del dualismo mente-cerebro"23.

De la educación de las damas para la conducta del espíritu en las ciencias y las costumbres, tiene una gran relevancia, siendo que el filósofo francés François Poulain de la Barre, "sienta las bases para un programa educativo igualitario y universal para ambos sexos (...) No cesa de reivindicar que el cerebro no tiene sexo, que el conocimiento y la educación es accesible a todos por igual y, por tanto, todos podemos participar en la vida pública"24.

La tercera obra del filósofo, François Poulain de la Barre, que habría que calificar de feminista, es La excelencia de los hombres contra la igualdad de los sexos, "donde Poulain intenta desmontar uno a uno, los argumentos en contra de la igualdad de las mujeres, refutándose a sí mismo y reconstruyendo argumentos basados en la razón"25.

En España, el estudio y análisis del pensamiento del filósofo François Poulain de la Barre, viene de la mano ${ }^{26}$, de la filósofa española Celia Amorós que lo define como "un precursor pre-ilustrado del feminismo (...) Su pensamiento representa un momento particularmente lúcido y pregnante de la autoconciencia crítica de la especie en una fase muy significativa de su evolución social y cultural"27.

Si el filósofo francés François Poulain de la Barre fue una de las primeras voces que se alzaron por la lucha de la igualdad entre mujeres y hombres, "la Revolución francesa y la Ilustración alumbraron el feminismo"28.

\footnotetext{
${ }^{22}$ León, Stella. (2010). François Poulain de la Barre: Feminismo y Modernidad. Astrolabio: Revista Internacional de Filosofía, № 11, p. 261.

${ }^{23}$ Amorós, Celia. (1997). Tiempo de feminismo. Sobre feminismo, proyecto ilustrado y postmodernidad. Madrid: Ediciones Cátedra, S.A., pp. 110 y ss.

${ }^{24}$ León, Stella. (2010). François Poulain de la Barre: Feminismo y Modernidad. Astrolabio. Revista Internacional de Filosofía, № 11, p. 262.

${ }^{25}$ Ibidem op. cit. p. 44.

${ }^{26}$ Ibidem op. cit. p. 38.

${ }^{27}$ Idem op. cit. p. 38.

${ }^{28}$ Varela, Nuria. (2018). Feminismo para principiantes. Barcelona: Penguin Random House Grupo Editorial, S. A. U., p. 23.
} 
Se comienzan a plantear en la etapa histórica de la Revolución francesa las siguientes cuestiones importantes: “¿Por qué están excluidas las mujeres? ¿Por qué los derechos sólo corresponden a la mitad del mundo, a los varones? ¿Dónde está el origen de la discriminación? ¿Qué podemos hacer para combatirla?"29.

Como siguientes voces feministas muy destacadas por su lucha contra la situación de opresión en la que se hallaba la mujer dentro de la Primera Ola del feminismo, se encuentran la voz de la escritora feminista francesa Olympe de Gouges, cuyo nombre original es Marie Gouze, que en 1791 escribe La declaración de los Derechos de la Mujer y la Ciudadana y la voz de la filósofa inglesa Mary Wollstonecraf que tan sólo un año después, en 1792, escribe la Vindicación de los derechos de la mujer, "considerada la obra fundacional del feminismo"30.

Como reacción a la Declaración de los Derechos del Hombre de 1789 en la que "se pregona a los cuatro vientos la igualdad universal y se deja sin derechos civiles y políticos a todas las mujeres" ${ }^{31}$, como asimismo asevera la filósofa española Celia Amorós, surge la obra de la feminista francesa Olympe de Gouges, La Declaración de los Derechos de la Mujer y de la Ciudadana que la sitúa como la precursora en el camino de la lucha y defensa de los derechos de la mujer.

En el Preámbulo de la Declaración de los Derechos de la Mujer y de la Ciudadana de 1791 la feminista Olympe de Gouges, plasmó:

Exponer en una Declaración solemne, los derechos naturales, inalienables y sagrados de la mujer a fin de que esta declaración recuerde sin cesar a todos los miembros del cuerpo social sus derechos y sus deberes, a fin de que los actos de poder de las mujeres y los del poder de los hombres puedan ser, en todo instante, comparados con el objetivo de toda institución política y sean más respetados por ella, a fin de que las reclamaciones de los ciudadanos, fundados a partir de ahora en principios simples e indiscutibles, se dirigen siempre al mantenimiento de la constitución, de las buenas costumbres y de la felicidad para todos.

Más allá del Preámbulo de la Declaración de los Derechos de la Mujer y de la Ciudadana, en el artículo primero de la Declaración, Olympe de Gouges, hizo constar las siguientes palabras: "La mujer nace libre y permanece igual al hombre en derechos, las distinciones sociales sólo pueden estar fundadas en la utilidad común". El artículo 1 de la Declaración de los Derechos del Hombre de 1789, estableció: "Los hombres nacen y permanecen libres e iguales en derechos. Las distinciones sociales solo pueden fundarse en la utilidad común". Como contenido esencial de la Declaración de los Derechos de la Mujer y de la Ciudadana, el artículo 10, recogió, las siguientes palabras: "La mujer tiene derecho a ser llevada al cadalso y del mismo modo a subir a la tribuna con tal que sus manifestaciones no alteren el orden público establecido por la ley".

\footnotetext{
${ }^{29}$ Varela, Nuria. (2018). Feminismo para principiantes. Barcelona: Penguin Random House Grupo Editorial, S. A. U., p. 14.

${ }^{30}$ Ibidem op. cit. p. 23.

${ }^{31}$ Amorós, Celia. (Dir), (2000). Feminismos, 10 palabras clave sobre mujer. Pamplona: Verbo Divino, p. 10.
} 
En la obra Los feminismos a través de la historia, se plantea la siguiente cuestión, sobre la etapa histórica de la Revolución francesa en la que Olympe de Gouges escribió la Declaración de los Derechos de la Mujer y de la Ciudadana:

Las mujeres no podían subir a la tribuna, pero sí podían subir al cadalso ¿Cuál era su falta? La prensa revolucionaria de la época lo explica claramente cuando establecían que habían transgredido las leyes naturales adjurando su destino de madres y esposas, queriendo ser hombres de estado. El nuevo código civil napoleónico, cuya extraordinaria influencia ha llegado prácticamente a nuestros días se encargaría de plasmar legalmente dicha ley natural ${ }^{32}$.

No todos los Ilustrados fueron incongruentes ${ }^{33}$, incide la feminista Nuria Varela.

En 1791 junto a la Declaración de los Derechos de la Mujer y de la Ciudadana de Olympe de Gouges, Marie Jean Antoine Nicolás de Caritat, Marqués de Condorcet, reclamó la admisión de las mujeres al derecho a la ciudadanía. Para el Marqués de Condorcet, diputado de la Asamblea Legislativa en Francia (tras la Constitución de 1791):

Los principios democráticos significaban que los derechos políticos eran para todas las personas, llegando a ironizar burlándose de los prejuicios de la época de la siguiente manera ¿Por qué unos seres expuestos a embarazos y a indisposiciones pasajeras no podían ejercer derechos de los que nunca se pensó en privar a la gente que tiene gota todos los inviernos o que se resfría fácilmente? ${ }^{34}$.

En 1792, un año después de la redacción de la Declaración de los Derechos de la Mujer y de la Ciudadana de Olympe de Gouges, la escritora feminista inglesa Mary Wollstonecraf, redactaba su obra más conocida, Vindicación de los derechos de la mujer.

La filosofa feminista Amelia Valcárcel, cuando valora y analiza la obra de Mary Wollstonecraf, Vindicación de los derechos de la mujer, señala: "La novedad teórica de Mary Wollstonecraf era que, por primera vez, llamaba privilegio al poder que siempre habían ejercido los hombres sobre las mujeres de forma natural, es decir, como si fuera un mandato de la naturaleza" ${ }^{35}$. Valcárcel, refiere, asimismo, sobre la filósofa feminista Mary Wollstonecraf:

Wollstonecraft decanta la polémica de los sexos ilustrada mediante el uso de categorías universales políticas cuya fuente se encuentra en el derecho natural racional. Pero a la vez inaugura la crítica de la condición femenina. Supone que bastantes de los rasgos de temperamento y conducta que son considerados propios de las mujeres son en realidad producto de su situación de falta de recursos y libertad. Así, desde su visión ilustrada niega

\footnotetext{
${ }^{32}$ De Miguel, Ana. (2011). Los feminismos a través de la historia. Recuperado de https://web.ua.es/es/sedealicante/ documentos/programa-de-actividades/2018-2019/los-feminismos-a-traves-de-la-historia.pdf.

${ }^{33}$ Varela, Nuria. (2018). Feminismo para principiantes. Barcelona: Penguin Random House Grupo Editorial, S. A. U., p. 34.

${ }^{34}$ Ibidem op. cit. p. 26.

${ }^{35}$ Varela, Nuria. (2018). Feminismo para principiantes. Barcelona: Penguin Random House Grupo Editorial, S. A. U, p. 31.
} 
que la jerarquía masculina sea otra cosa que un privilegio injusto avalado por prejuicios inmemoriales ${ }^{36}$.

En la obra Vindicación de los derechos de la mujer, Mary Wollstonecraf, realizó, "una crítica razonada e inteligente a aquellos pensadores que conceptualizaban la naturaleza femenina como inferior a la masculina y que, en consonancia con ello, postulan la exclusión de las mujeres de sus derechos civiles y políticos"37.

Entre los autores que destacaron por tener un pensamiento de minusvaloración de la mujer y profundamente patriarcal, Mary Wollstonecraf, procede a rebatir las palabras del filósofo Jean Jacques Rousseau, aunque es necesario recordar, que "la autora inglesa no critica exclusivamente a Rousseau sino también, a cuantos escritores habían conceptualizado un modelo de mujer inferior al varón"38.

Mary Wollstonecraf selecciona para su análisis y rebate una de las obras más destacadas del filósofo suizo Jean-Jacques Rousseau. En el capítulo V de la obra Emilio o de la educación del siglo XVIII, Rousseau hace uso de un personaje ficticio, Sofía, para desarrollar lo que él denominaba:

La verdadera naturaleza de la mujer, de tal modo que presenta a Sofía con una naturaleza inferior y social subordinada a la de Emilio (...) Subrayando con precisión y claridad la igualdad como un rasgo natural de pura naturaleza, por lo que hace una operación que consiste en aislar a las mujeres y sacarlas de su carácter históricamente construido y devolverlas a un estado presocial que establece la desigualdad de los sexos: Una gran parte de Vindicación de los derechos de la mujer está consagrada a mostrar las groseras incoherencias del más radical de los pensadores de la Ilustración ${ }^{39}$.

Hace uso de las siguientes palabras la feminista Mary Wollstonecraf cuando reflexiona sobre la obra de Emilio o de la educación de Jean-Jacques Rousseau:

Probablemente yo he tenido la oportunidad de observar más niñas en mi infancia que Jean Jacques Rousseau. Puedo recordar mis propios sentimientos y he observado a mi alrededor con detenimiento, en pocas palabras, niñas y niños jugarían juntos, si no se inculcara la distinción de sexos mucho antes de que la naturaleza haga alguna diferencia, publicando una doctrina cargada de daño ${ }^{40}$.

Las ideas más importantes de Mary Wollstonecraf en su obra Vindicación de los derechos de la mujer quedan reflejadas en el capítulo de conclusiones de la siguiente manera:

\footnotetext{
${ }^{36}$ Valcárcel, Amelia. (2001). La memoria colectiva y los retos del feminismo. Santiago de Chile: Naciones Unidas (CEPAL). Serie Mujer y Desarrollo, no 31, p. 12.

${ }^{37}$ Amorós, Celia. (2005). Teoría feminista: De la Ilustración a la globalización. Madrid: Minerva Ediciones, S.L., p. 135.

${ }^{38}$ Idem op. cit. p. 135.

${ }^{39}$ Amorós, Celia. (2005). Teoría feminista: De la Ilustración a la globalización. Madrid: Minerva Ediciones, S.L., p. 136.

${ }^{40}$ Wollstonecraf, Mary. (1994). Vindicación de los derechos de la mujer. Madrid: Cátedra-Instituto de la Mujer, pp. 162-163.
} 
1. Lo que dicen para los hombres lo extiendo al género humano, insistiendo en que la moral debe estar fijada a principios inmutables en todas las cosas (...) 2. No se puede llamar racional o virtuoso a un ser que obedece a otra autoridad que no sea la razón (...) 3. Para que las mujeres se conviertan en miembros útiles para la sociedad se las debe conducir a través de la educación y la formación (...) 4. La idea de que de una revolución en los modales femeninos basados en la formación e igualdad entre hombres y mujeres podrían esperarse los efectos más saludables, tendentes a mejorar la humanidad ${ }^{41}$.

La feminista Mary Wollstonecraf, inicia su vida y la acaba, repitiéndose:

Las monstruosas preguntas que su hija Mary Shelley pondría luego en boca del sueño de la razón de Frankenstein cuando éste se descubrió así mismo como único y monstruoso, definida su identidad a través del terror y el rechazo que su mera apariencia suscitaba en los demás: ¿Quién soy? ¿Qué soy? ¿De dónde vengo? ¿Cuál es mi destino?².

En 1775 se prohíbe a las mujeres la posibilidad de asistir a las Asambleas políticas. Posteriormente, el Código Civil francés de 1804, conocido oficialmente como Código Napoleónico a partir de 1807, imitado por toda Europa, hace de nuevo del matrimonio un contrato desigualitario para las partes. El artículo 321 del Código Civil determinaba así, la obediencia de la mujer al marido y, al mismo tiempo, sólo se le concedía el divorcio a la mujer en el caso de que el marido, llevase a su concubina al domicilio conyugal ${ }^{43}$.

El Código Civil francés o Código Napoleónico, hace concreción la filósofa Amelia Valcárcel, consagró la minoría de edad perpetua de las mujeres:

Eran consideradas hijas y madres en poder de sus padres, esposos e incluso hijos (...) Las mujeres no tenían derecho a administrar su propiedad, fijar o abandonar su domicilio, ejercer la patria potestad, mantener una profesión o emplearse sin permiso, rechazar a un marido violento. La obediencia, el respeto, la abnegación y el sacrificio quedaban fijados como sus virtudes obligatorias ${ }^{44}$.

Otra de las formas en que las mujeres de la etapa de la Ilustración y Revolución francesa se manifestaron en contra de la subordinación histórica de la mujer fue a través de los Cuadernos de Queja, redactados, en 1789. Creados para dar a conocer y hacer llegar las reivindicaciones de las mujeres a los Estados generales. Las mujeres "quedaron excluidas de la Asamblea General y entonces se volcaron en los Cuadernos de Quejas donde hicieron oír sus voces por escrito, desde las nobles hasta las religiosas pasando por las mujeres del pueblo" ${ }^{45}$. Los citados Cuadernos de Queja, "suponían un testimonio colectivo de las esperanzas de cambio de las mujeres" ${ }^{\prime 4}$.

\footnotetext{
${ }^{41}$ Ibidem op. cit. pp. 390-394.

${ }^{42}$ Ibidem op, cit. p. 14.

${ }^{43}$ Varela, Nuria. (2018). Feminismo para principiantes. Barcelona: Penguin Random House Grupo Editorial, S. A. U., pp. 41-42.

${ }^{44}$ Valcárcel, Amelia. (2001). La memoria colectiva y los retos del feminismo. Santiago de Chile: Naciones Unidas (CEPAL). Serie Mujer y Desarrollo, no 31, p. 13.

${ }^{45}$ Varela, Nuria. (2018). Feminismo para principiantes. Barcelona: Penguin Random House Grupo Editorial, S. A. U., p. 30.

${ }^{46}$ Blanco, Oliva. (2000). Olimpia de Gouges (1748-1793). Madrid: Ediciones del Orto, p. 38.
} 
El movimiento feminista seguirá con la lucha que iniciaron las mujeres del siglo XVIII. Mujeres que seguían sin poder disfrutar de ningún derecho, "sin capacidad de ciudadanía y fuera del sistema normal educativo, (...) fuera del ámbito completo de los derechos y bienes liberales. Por ello el obtenerlos, el conseguir el voto y la entrada en las instituciones de alta educación, se convirtieron en los objetivos del sufragismo" ${ }^{\prime 4}$.

\section{La Segunda Ola feminista ( $2^{\mathrm{a}}$ mitad del siglo XIX $-1^{\text {er }}$ tercio del siglo XX)}

"Negamos el derecho de que cualquier parte de la especie humana decida por otra parte, o cualquier individuo por otro individuo qué es y qué no es la esfera propia de cada uno. La esfera propia es, para todos los seres humanos, la más ancha y la más alta que puedan conseguir"

HARRIET TAYLOR MILL

El origen inmediato del movimiento a favor de los derechos de la mujer del siglo XIX, fue, la cruzada antiesclavista: "En el Congreso Mundial Antiesclavista celebrado en Londres en 1840, un grupo de delegadas americanas se vieron excluidas del mismo, aludiendo a que su participación activa ofendería a la opinión pública británica, relegándolas a las tareas domésticas y, negándoles por tanto la voz y la palabra"48.

En 1848, nace la Declaración de Séneca Falls, conocida, asimismo, como Declaración de Sentimientos o de Pareceres. El primer texto del sufragismo organizado por Lucretia Mott y Elizabeth Cady Stanton.

La Declaración de Séneca de 1848 fue un texto desarrollado a partir de la Declaration of Independence of the Thirtheen Colonies de 1776, en la que se reemplazó las palabras King Georg por all men, al ser los hombres los que oprimían a las mujeres y, padres los fundadores los que redactaron la Declaration of Independence e, incluyeron, una relación de reclamaciones y quejas de las mujeres en aquel periodo histórico. Entre las quejas y reclamaciones que recogía la Declaración de Séneca Falls se encontraban esas denuncias por las restricciones sobre todo políticas a las que estaban sometidas las mujeres: "Las mujeres no podían votar, ni presentarse a elecciones, ni ocupar cargos políticos, ni afiliarse a partidos políticos o asistir a reuniones políticas"49.

En torno al derecho al voto de las mujeres y a la igualdad entre hombres y mujeres establecieron, así, dos de los considerandos de la Declaración de Séneca Falls: "es deber de las mujeres de este país asegurarse el sagrado derecho del voto", señaló el primer considerando, "la igualdad de los derechos humanos es consecuencia del hecho de que toda la raza humana es idéntica en cuanto a capacidad y responsabilidad", determinó el segundo considerando.

\footnotetext{
${ }^{47}$ Valcárcel, Amelia. (2001). La memoria colectiva y los retos del feminismo. Santiago de Chile: Naciones Unidas (CEPAL). Serie Mujer y Desarrollo, no 31, p. 14.

${ }^{48}$ Ramírez, María. Dolores., González, Juan., Cerrato, Daniele., y Martín, Milagro. (2011). La querella de las mujeres de España a Latinoamérica. Vol. 2. Sevilla: Arcibel.

${ }^{49}$ Miyares, Alicia. (1999). 1848: El manifiesto de Seneca Falls. Revista Leviatán, no 75, pp. 135-158.
} 
Las feministas americanas Elizabeth Cady Stanton y Susan B. Anthony, fundaron en 1868, la Asociación Nacional pro Sufragio para la Mujer y, tan solo un año después, en 1869, Wyoming se convirtió en el primer Estado que reconoció el derecho al voto de las mujeres ${ }^{50}$.

La activista por los derechos de la mujer y abolicionista, Sojourner Truth, fue una de las numerosas voces que se unen al feminismo y al sufragismo en la lucha por el derecho al voto. Sojourner fue la única mujer afroamericana abolicionista y defensora de los derechos de la mujer que consiguió asistir a la primera Convención Nacional de los Derechos de la Mujer en Worcester en 1850. El discurso realizado por Sojourner Truth, "abría el camino para el desarrollo del feminismo de las mujeres negras en América y demostraba que las supuestas debilidades naturales de las mujeres, o, sus incapacidades (...) sólo eran disquisiciones absurdas e interesadas"51. Sojourner, "hizo honor a su nombre -literalmente, Verdad Viajera- y pregonó allí donde pudo algunas verdades que cuestionaban aún más los discursos que justificaban la exclusión de las mujeres" 52 .

En 1861, el filósofo inglés John Stuart Mill escribió su conocida obra La sujeción de la mujer, aunque no la publicó hasta 1869. Obra fundamental del feminismo y que contribuye de una manera esencial en la lucha de las sufragistas contra los prejuicios históricos sobre la mujer. En palabras de las filósofas feministas Ana de Miguel y Celia Amorós, la obra de Mill, La sujeción de la mujer, es "una de las obras que más y mejor contribuyeron a clarificar la auténtica maraña ideológica patriarcal de la sociedad decimonónica, a mirar con ojos nuevos y lograr ver a través del gran chorro de tinta de calamar que oscurecía la condición real de las mujeres y se sintetizaba en la apelación final a la naturaleza de la mujer"53. Amorós, refiere cómo el historiador británico Richard J. Evans detalla la influencia de la obra de John Stuart Milll en el movimiento de la mujer cuando reflexiona: "El ensayo de Mill, La sujeción de la mujer publicado en 1869, fue la biblia de las feministas"54.

El feminismo respeta al filósofo feminista John Stuart Mill por su obra La sujeción de la mujer y por su trabajo como político diputado en la Cámara de los Comunes (el Parlamento inglés), donde pretendió cambiar la palabra de hombre por persona en la reforma electoral que se deliberaba en aquella época ${ }^{55}$.

Veintiséis naciones ya habían reconocido a la mujer en distinto grado, derechos civiles y políticos hacia 1920 y, en 1964 dicho número llegó a 104, por todo ello, nos dice la feminista Kate Millett, "resulta indudable que se produjo un profundo cambio social cuya simiente ya había sido plantada en Inglaterra y América durante el siglo XIX"56.

\footnotetext{
${ }^{50}$ Varela, Nuria. (2018). Feminismo para principiantes. Barcelona: Penguin Random House Grupo Editorial, S. A. U., pp. 49-50.

${ }^{51}$ Varela, Nuria. (2018). Feminismo para principiantes. Barcelona: Penguin Random House Grupo Editorial, S. A. U., p. 57.

52 Ibidem op. cit. p. 56.

${ }^{53}$ Amorós, Celia., De Miguel, Amelia. (Eds.), (2005). Teoría feminista: De la Ilustración a la globalización. Madrid: Minerva Ediciones, S.L., p. 178.

${ }^{54}$ Idem op. cit. p. 178.

${ }^{55}$ De Miguel, Ana. (1994) Deconstruyendo la ideología patriarcal. Un análisis de la “Sujeción de la mujer”, en Amorós, Celia. (coord.), Historia de la teoría feminista, pp. 49-68 (p. 52).

${ }^{56}$ Millett, Kate. (1969). La política sexual. Madrid: Ediciones Cátedra, S. A., p. 160.
} 
Recuperando otra voz feminista que ha sido invisibilizada a través de la historia y que luchó contra las injusticias y discriminación fragante que sufría la mujer; la feminista francesa Flora Tristán, como sus predecesoras en el feminismo, une tanto vida, como obra, como denuncia ${ }^{57}$. En 1843, publica su obra Unión Obrera donde refiere: "Todas las desgracias del mundo provienen de este olvido que hasta hoy se ha hecho de los derechos naturales e imprescriptibles de la mujer"58. Desarrollando esta idea de injusta situación para las mujeres, Tristán, seguía reflexionado, así: "Reclamo derechos para la mujer porque es el único medio para obtener su rehabilitación frente a la Iglesia, frente a la ley y frente a la sociedad"59. Tristán, señaló como idea básica: "El reconocimiento, en principio, de la igualdad de derechos del hombre y de la mujer como único medio de construir la unidad humana"60.

Puesta de manifiesto la lucha mantenida en el tiempo por conseguir equilibrar en derechos al hombre y mujer, llevada a cabo, por mujeres y hombres feministas que se comprometieron con su vida y su obra por la igualdad en la Primera Ola y Segunda Ola del feminismo, se empiezan a vislumbrar verdaderos avances hacia la equiparación de derechos de hombres y mujeres, con la consecución de un hito histórico para el movimiento feminista: El derecho al voto de la mujer y la entrada de las primeras mujeres en las Universidades.

Se puede concretar, cómo fue el 28 de Mayo de 1917 cuando se aprobó la Ley de Sufragio femenino en Inglaterra. La mujer obtuvo el derecho al voto pero este derecho fue otorgado únicamente a las mujeres mayores de 30 años. En 1927 se nivela el voto femenino y masculino en la misma edad, pudiendo votar y ser votadas en Inglaterra todas las mujeres mayores de 21 años.

Si hacemos referencia a la consecución del derecho al voto por la mujer en EEUU, no fue hasta 1918, cuando el presidente Wilson apoyó al movimiento sufragista aprobando en la Cámara de Representantes, la conocida Decimonovena Enmienda, pero no sería hasta 1920, cuando el voto femenino sería posible en EEUU.

Hacia el final de la Segunda Guerra Mundial en 1945 es cuando la gran mayoría de los Estados, que no conformaban en aquella etapa histórica una dictadura, reconocieron el derecho al voto a las mujeres. Haciendo memoria, la filósofa Amelia Valcárcel, señala:

Sin embargo, ya podían contabilizarse varios éxitos del movimiento feminista, dos países no europeos, pero ligados a la órbita de Gran Bretaña, fueron los adelantados en reconocer el derecho al voto a las ciudadanas, así Nueva Zelanda lo aprobó en 1893 y Australia en 1902. Mientras tanto, en Europa, entre los países nórdicos, Finlandia aprobó el voto en 1906, Noruega en 1913, Dinamarca e Islandia en 1915, en Francia, el lastre del Código napoleónico y el conservadurismo de una gran parte de la sociedad francesa retrasarían largos años la consecución del derecho al voto, la IV República lo aprobó en 1946. En Holanda y

\footnotetext{
${ }^{57}$ Varela, Nuria. (2018). Feminismo para principiantes. Barcelona: Penguin Random House Grupo Editorial, S. A. U., p. 70.

${ }^{58}$ Tristán, Flora. (2003). Feminismo y socialismo. Antología. Madrid: Los libros de la Catarata, p. 8.

${ }^{59}$ Tristán, Flora. (1843). La Unión Obrera. Barcelona: De Barris, p. 131.

${ }^{60}$ Tristán, Flora. (1843). La Unión Obrera. Barcelona: De Barris, p. 194.
} 
la Unión Soviética, en 1917, Austria, Polonia, Checoslovaquia y Suecia en 1918, Sudáfrica en 1930, Brasil en 1934, Rumanía en 1935 o Filipinas en 1937. Tras la II Guerra Mundial, además de Francia, el voto femenino sería concedido a la inmensa mayoría de países del mundo, coincidiendo con las independencias que sucedieron al fin de los grandes imperios coloniales ${ }^{61}$.

La feminista española Clara Campoamor es considerada como la única sufragista del mundo que consiguió el derecho al voto desde la tribuna de un Parlamento, el 1 de Octubre de 1931.

Reflexionando en torno al movimiento sufragista la filósofa española Amelia Valcárcel, refiere:

Tanto el derecho al voto cómo los derechos educativos marcharon a la par apoyándose mutuamente. (...) El espinoso camino educativo se conectaba directamente con el de los derechos políticos (...) La pertinaz lucha en la opinión y en el cambio de posiciones de las mujeres en la educación y en los empleos llegaba a su fin. Los bienes liberales habían sido conseguidos y, tanto el sufragismo como la misoginia romántica habían cubierto su tramo. Las cosas eran ahora diferentes ¿Pero lo eran? ${ }^{62}$.

La filósofa francesa Simone de Beauvoir, con su obra El segundo sexo, puso la base teórica para una nueva etapa del feminismo: La Tercera Ola feminista ${ }^{63}$.

\section{La Tercera Ola feminista ( $2^{a}$ mitad del siglo XX - comienzos del siglo XXI)}

"No se nace mujer: llega una a serlo" SIMONE DE BEAUVOIR

La feminista francesa Simone de Beauvoir y su conocido ensayo El segundo sexo escrito en 1949, en palabras de la filósofa española Teresa López en El feminismo existencialista de Simone de Beauvoir y el lugar de El segundo sexo en la historia del feminismo, "marca un antes y un después en la historia de la teoría feminista (...) no sólo porque vuelve a poner en pie al feminismo después de la II Guerra Mundial, sino porque constituye el ensayo más completo sobre la condición de la mujer"64. Lo primero que se le hace evidente a la mujer es que "ella aparece como la otra"65. No hay igualdad con el hombre; no hay ni reciprocidad ni reconocimiento, siempre se encuentra en asimetría en relación al hombre

\footnotetext{
${ }^{61}$ Valcárcel, Amelia. (2001). La memoria colectiva y los retos del feminismo. Santiago de Chile: Naciones Unidas (CEPAL). Serie Mujer y Desarrollo, no 31, pp. 15-26.

${ }^{62}$ Ibidem op. cit. pp. 17-20.

${ }^{63}$ Varela, Nuria. (2018). Feminismo para principiantes. Barcelona: Penguin Random House Grupo Editorial, S. A. U., pp. 81-82.

${ }^{64}$ López, Teresa. (2005). El feminismo existencialista de Simone de Beauvoir. En Celia. Amorós., Ana. De Miguel. (Eds.), Teoría feminista: De la Ilustración a la globalización. Madrid: Minerva Ediciones, S.L., p. 338.

${ }^{65}$ Ibidem op. cit. p. 340.
} 
“y para poder llegar a su plena realización humana es necesario que hombre y mujer se reconozcan mutuamente como personas libres e independientes"66.

Como voces feministas destacadas de la Tercera Ola del feminismo, la teórica feminista Betty Friedan es considerada una voz, muy importante, dentro del nuevo feminismo norteamericano que surge a mediados del siglo XX. Feminismo que dio como resultado la creación de la asociación feminista Organización Nacional de Mujeres (NOW). "Ha llegado el momento de enfrentarse, como naciones concretas a las condiciones que ahora impiden a las mujeres disfrutar de la igualdad de oportunidades y de la libertad de elección a las que tienen derecho, como norteamericanas y como seres humanos"67, escribió Betty Friedan en la Declaración de Principios de NOW.

La autora feminista Betty Friedan es conocida por dos de sus obras más importantes: La mística de la feminidad escrita en 1963 y La segunda fase escrita en 1981.

La mística de la feminidad de Betty Friedan, gira en torno a la frase "el malestar que no tiene nombre (...) ¿Es esto todo? (...) No hubo una palabra para aquel anhelo entre los millones de palabras escritas sobre las mujeres, para las mujeres, en las columnas, los libros y los artículos de expertos que les decían a las mujeres que su papel consistía en realizarse como esposas y madres (...) No podían aspirar a un destino más elevado que la gloria de su propia feminidad"68.

Los años 70 fueron años de una intensa agitación política en los que bajo el eslogan "lo personal es político", las feministas fueron identificando "como centros de poder y dominación del hombre sobre la mujer ámbitos o áreas de la vida que hasta entonces eran privados, revolucionando de esta manera la teoría política al analizar las relaciones de poder existentes tanto en la familia y sexualidad. Consideraban así que los hombres reciben beneficios psicológicos, sexuales y económicos del sistema patriarcal"69.

De esta manera problemas "tan sumamente enraizados y al mismo silenciados en nuestra sociedad como la violencia de género su pusieron encima de la mesa (...) Si lo personal es político, las leyes no se pueden quedar a la puerta de casa"70.

El feminismo que surge en los 70 tuvo dos obras fundamentales: La política sexual de Kate Millett, que escribió, en 1969 y, la obra La dialéctica del sexo de la autora feminista Shulamith Firestone, editada en 1970.

En ambas obras, La política sexual y La dialéctica del sexo, se definen conceptos tan importantes para el movimiento feminista como patriarcado y género ${ }^{71}$. El patriarcado se define como "un sistema de dominación sexual que es, además, el sistema básico de dominación sobre el que se levantan el resto de las dominaciones, como la de clase o la de raza;

\footnotetext{
${ }^{66}$ Varela, Nuria. (2018). Feminismo para principiantes. Barcelona: Penguin Random House Grupo Editorial, S. A. U., p. 70.

${ }^{67}$ Friedan, Betty. (2003). Mi vida hasta ahora. Madrid: Cátedra, p. 236.

${ }^{68}$ Friedan, Betty. (2009). La mística de la feminidad. Madrid: Cátedra, p. 51.

${ }^{69}$ De Miguel, Ana. (2002). Feminismos. En Celia. Amorós. (Dir.). 10 palabras clave sobre mujer. Pamplona: Editorial Verbo Divino, p. 242.

${ }^{70}$ Varela, Nuria. (2018). Feminismo para principiantes. Barcelona: Penguin Random House Grupo Editorial, S. A. U., p. 105.

${ }^{71}$ Idem op. cit. p. 105.
} 
el patriarcado es un sistema de dominación masculina que determina la opresión y la subordinación de las mujeres"72. El género expresa "la construcción social de la feminidad"73. Una vez puesto el germen de lo personal es político, a partir de 1970, el movimiento feminista nunca más volvió a ser lo mismo.

\section{Una aproximación a la Cuarta Ola feminista (siglo XXI - )}

$\mathrm{Al}$ igual que las Olas del feminismo previas han tenido una serie de objetivos que se han ido consiguiendo a través del reconocimiento de derechos básicos para la mujer que, prácticamente anteayer, parecían inalcanzables, como el derecho a la educación, el derecho al voto, los mismos derechos de ambos cónyuges dentro del matrimonio, el divorcio, el derecho al aborto, etc., la Cuarta Ola del feminismo asienta sus bases teóricas en la lucha contra las formas de violencia hacia la mujer, incluida la violencia sexual y la prostitución. La autora Rosa Cobo, refiere así, respecto a los objetivos de la Cuarta Ola feminista: "El cuerpo vindicativo de la cuarta ola feminista es, sin duda, la violencia sexual. La violencia es un problema crónico y global de las mujeres, que la padecen tanto las de los países periféricos como las de los centrales. La violencia sexual es un poderoso mecanismo de control social que impide a las mujeres tanto apropiarse del espacio público como hacer uso de su autonomía y libertad (...) La lucha contra la violencia sexual ha calado tan hondo entre las mujeres de todas las edades y ha tomado tal fuerza que está ampliando el marco de la definición de violencia, incluso de aquellas que han estado más naturalizadas"74, como la prostitución.

En torno a la paridad entre el hombre y la mujer, existente en la actualidad, la feminista española Alicia Miyares, refiere:

La paridad existente, en la representación política, no se ha logrado extender a otras esferas sociales: no ha sido en absoluto casual que este 8 de marzo se hubiera visto acompañado de manifiestos específicos de mujeres periodistas, deportistas, científicas, académicas, editoras, juristas, actrices, etc., demandando paridad y la quiebra del techo de cristal (...) Esta cuarta ola del feminismo no se configura solo en torno a la vindicación de los derechos de las mujeres y su efectividad real y no formal, sino que además, y de ahí su novedad, parece hacer tomado conciencia de las sutiles formas de violencia, acoso y explotación que sufren las mujeres y no así los varones ${ }^{75}$.

La feminista española Luisa Posada, analiza y reflexiona, en torno a la existencia de la Cuarta Ola del feminismo:

\footnotetext{
${ }^{72}$ De Miguel, Ana. (2005). La construcción de un marco feminista de interpretación: La violencia de género. Cuadernos de Trabajo Social. Vol. 18, p. 238.

${ }^{73}$ Varela, Nuria. (2018). Feminismo para principiantes. Barcelona: Penguin Random House Grupo Editorial, S. A. U., p. 115.

${ }^{74}$ Cobo, Rosa. (2019). La cuarta ola feminista y la violencia sexual. Revista Interuniversitaria de cultura Paradigma, pp. 134-138 (p. 138).

${ }^{75}$ Miyares, Alicia. (11/03/2018). La "Cuarta Ola" del feminismo, su Agenda. Tribuna Feminista. Recuperado de https://tribunafeminista.elplural.com/2018/03/la-cuarta-ola-del-feminismo-su-agenda/.
} 
Si hablamos de una $4^{\mathrm{a}}$ ola feminista, habrá que establecer que hablamos de algo reactivo, ya que toda ola es reactiva, es decir, es algo que supone un avance frente a un repliegue. Hablamos entonces de una $4^{\underline{a}}$ ola como reacción, como impulso hacia delante, frente a la actual contrarreacción patriarcal (...) Tras las grandes conquistas feministas, lo que hoy está sacando al feminismo a las calles y haciéndolo un movimiento de masas yo diría que es -no sólo pero sí centralmente- una auténtica insurrección, una rebelión contra la violencia patriarcal. Una violencia en sentido amplio, que se expresa de muchas maneras: como violación, como acoso, como maltrato, como asesinato, como desigualdad económica y laboral, como pornografía, como prostitución, como trata... Hoy habría que añadir otros fenómenos de este poder sexualmente expresado, como la práctica de los vientres de alquiler. Por tanto, en cuanto al qué de esta cuarta ola, el qué la impulsa, yo diría que fundamentalmente es una rebelión contra lo que creo que se está configurando como el nuevo paradigma del patriarcado: el patriarcado violento (...) En nuestro mundo globalizado la realidad material de las condiciones de vida de muchas mujeres exige todavía pensar desde el feminismo un proyecto de emancipación social, político cultural y personal ${ }^{76}$.

La feminista española Amparo Rubiales, refiere, sobre el inicio de la Cuarta Ola feminista:

La cuarta ola del feminismo, la del final del patriarcado, tiene (...) su momento culminante tras la marcha de las mujeres americanas, el día siguiente a la toma de posesión de Trump (21 de enero 2017), en defensa de la dignidad de las mujeres (...) Las denuncias por acosos sexuales del Metoo se convierten en un tsunami que está sacudiendo los cimientos de la sociedad patriarcal. Todo ello culmina con las masivas manifestaciones del 8 de marzo en todo el mundo (...) Hay que resistir sin retrocesos. Contra las mujeres se ejercen toda clase de violencia y la violencia es la mayor expresión de intolerable desigualdad que sufrimos ${ }^{77}$.

Entre las grandes manifestaciones y encuentros globales de mujeres y hombres feministas que han determinado el comienzo de la Cuarta Ola del feminismo en la horquilla cronológica que abarca desde el 2011 hasta la actualidad, en 2020, se encuentran las siguientes:

El 13 de Febrero de 2011 se celebró una movilización masiva de mujeres italianas que luchaban por su dignidad y contra su consideración como objetos sexuales. Las mujeres denunciaron en Italia "un sistema de poder trasversal y mediático que prima la aparición en televisión y la venta del cuerpo sobre la formación, el pensamiento y el trabajo"78. La manifestación tuvo como consigna "si no ahora cuando" ("se non ora quando").

\footnotetext{
${ }^{76}$ Posada, Luisa. (22/10/2018). El sujeto político feminista en la 4⿳a ola. El Diario. Recuperado de https://www.eldiario.es/tribunaabierta/sujeto-politico-feminista-ola_6_827727257.html.

${ }^{77}$ Rubiales, Amparo. (3/04/2018). La cuarta ola feminista. Huffington Post. Recuperado de https://www.huffingtonpost.es/amparo-rubiales/la-cuarta-ola-feminista_a_23401645/.

${ }^{78}$ Mora, Miguel. (13/02/2011). Un millón de mujeres dicen no a Berlusconi y al machismo. El País. Recuperado de https://elpais.com/internacional/2011/02/13/actualidad/1297551605_850215.html.
} 
A continuación, el 3 de Junio de 2015, tuvo lugar una manifestación multitudinaria organizada en Argentina, contra la violencia machista, y, el feminicidio. El movimiento tuvo como desencadenante el asesinato de una joven de 14 años por su novio de 16 años en Mayo de 2015. Fue "una de las razones para que organizaciones civiles y políticas se unieran a esta movilización que se realizará en más de 80 pueblos y ciudades argentinas (...) La legislación argentina incluyó en 2012 el crimen de feminicidio dentro de su código penal para castigar los asesinatos de mujeres en casos de violencia de género. En Marzo de 2009 se sancionó la ley 26.485 para prevenir, sancionar y erradicar la violencia contra las mujeres en los ámbitos en que desarrollen sus relaciones interpersonales"79.

El movimiento tuvo como consiga "ni una menos". El movimiento no perdió impulso y se repitió, posteriormente, el 3 de Junio de 2016, con la consigna "vivas nos queremos" y, el 3 de Junio de 2017, con la frase "basta de violencia machista y complicidad estatal"

El 21 de Enero de 2017, se organizó una de las manifestaciones más multitudinarias de EEUU (Women's March), impulsada por el movimiento feminista y, motivada, por la repulsa y malestar causado por el nombramiento del presidente Donald Trump que es conocido por sus comentarios denigrantes hacia la mujer. La Marcha de las Mujeres de Washington tuvo su réplica en otras ciudades de Estados Unidos, Londres, Paris, Roma, Madrid, Barcelona, etc. El movimiento estuvo arropado por "616 marchas hermanas en todo Estados Unidos y en el resto del mundo" ${ }^{11}$.

Posteriormente, el 5 de Octubre de 2017, el periódico The New York Times publicó el conocido como "el caso Weinstein" en el que se acusó al productor de Hollywood, Harvey Weinstein, de acoso y agresión sexual a numerosas mujeres. "El caso Weinstein" supuso para el movimiento poner "el foco en la violencia sexual y que encuentra en el feminismo su columna vertebral (...) Mujeres de todo el mundo compartieron sus propias historias bajo el hashtag MeToo"82.

El 8 de Marzo de 2017, se produjo el primer paro internacional de mujeres. A la manifestación se adhirieron mujeres de 57 países, incluidas mujeres saharauis y mujeres de Kurdistán. Se hizo uso del hashtag \#8M y de las consignas "ni una menos, nos queremos vivas", "ni un paso atrás", "si nosotras paramos todo se para", "paramos para cambiarlo todo", “juntas somos más". Con la consigna "ni una menos, vivas nos queremos”, las mujeres argentinas, llevaron a cabo, la primera huelga global de trabajo productivo y reproductivo ${ }^{83}$.

\footnotetext{
${ }^{79}$ CNN español. (3/06/2015). "Ni una menos" la movilización que pide parar la violencia de género en Argentina. Recuperado de https://cnnespanol.cnn.com/2015/06/03/ni-una-menos-la-movilizacion-que-pide-parar-la-violenciade-genero-en-argentina/.

${ }^{80}$ Rodríguez, María Eugenia., Lourdes, Lucía., Barba, Ana., y Bravo, Paloma. ¿Una nueva ola feminista? Espacio Público. Recuperado de http://www.espacio-publico.com/el-despertar-del-nuevo-feminismo.

${ }^{81}$ El Diario. (21/01/2017). Cientos de mujeres de todo el mundo marchan contra Trump. Recuperado de https:// www.eldiario.es/internacional/Cientos-miles-mujeres-marchan-Trump_0_604039983.html.

${ }^{82}$ Requena, Ana., Borraz, Marta. (4/10/2018). El movimiento \#MeToo, corazón de una nueva ola feminista que pone el foco en la violencia sexual. El Diario. Recuperado de https://www.eldiario.es/sociedad/movimiento-MeToo-corazonfeminista-violencia_0_821368506.html.

${ }^{83}$ Argumentario de la huelga del 8 de marzo. Hacia la huelga feminista. Recuperado de http://hacialahuelgafeminista.org/wp-content/uploads/2018/02/argumentario_8M.pdf.
} 
En España, el 8 de Marzo de 2018, miles de mujeres se manifestaron "en las calles de ciudades y pueblos españoles tras una jornada pacífica de huelga. Hacía años que no se recordaban manifestaciones tan masivas ni tampoco intergeneracionales"84.

En la lucha contra la violencia sexual hacia las mujeres que se produce en el ámbito público en España, la Sentencia no 38/2018, de 20 de Marzo, de la Sección Segunda de la Audiencia Provincial de Navarra, conocida como la Sentencia de "la Manada", supuso un punto de inflexión en la tipificación de la regulación de los delitos contra la libertad e indemnidad sexual en el Código Penal español ${ }^{85}$.

Como indicadores de la existencia de una Cuarta Ola feminista habría que destacar:

1) El feminismo tiene un carácter intergeneracional, con una cantidad cada vez mayor de mujeres jóvenes, que "ha sido capaz de colocar en el centro simbólico de la sociedad un significante, la necesidad de justicia para las mujeres" 86 y se ha hecho global; no hay un lugar del mundo donde no haya feminismo. En palabras de Rosa Cobo, "las movilizaciones que se han desarrollado en este último lustro en diversos países anuncian lo que ya, sin duda, puede ser definido como la cuarta ola feminista (...) Por primera vez en la historia no encontramos un solo país sin presencia de organizaciones feministas o asociaciones que defiendan los derechos de las mujeres. Y este hecho, la globalización del feminismo es, sin duda, una característica de la cuarta ola" ${ }^{\prime 2}$. Se han celebrado manifestaciones feministas en lugares donde las mujeres no tienen reconocidos sus derechos como ciudadanas. Países donde la desigualdad, discriminación y violencia que sufren las mujeres, son aún en pleno siglo XXI, permitidas por su regulación legal, sociedad, cultura, religión y familia. Se han organizado manifestaciones feministas en países como Mosul, Bagdad, Turquía, Arabia Saudí e, Irán: “Las injustas leyes de matrimonio, divorcio, herencia, etc., han convertido a las mujeres en ciudadanas de segunda clase. Las mujeres no tienen protección legal contra la violencia doméstica y el acoso en la calle (...) Sigue en vigor el sistema de tutela que reduce a las mujeres a eternas menores y está en la base de esas discriminaciones anacrónicas"88.

En Irán, recientemente, ha sido encarcelada la Abogada defensora de los Derechos Humanos de la Mujer, Nasrín Sotudé, por defender a mujeres iraníes que se quitan el hijad en el espacio público. Sotudé, fue juzgada, el 30 de Diciembre de 2018 en rebeldía tras no

\footnotetext{
${ }^{84}$ Cobo, Rosa. (2019). La cuarta ola feminista y la violencia sexual. Revista Interuniversitaria de cultura Paradigma, pp. $134-138$ (p. 134).

${ }^{85}$ Sentencia no 38/2018, de 20 de Marzo, de la Sección Segunda de la Audiencia Provincial de Navarra, conocida como la Sentencia de "la Manada". Recuperado de https://cdn.20m.es/adj/2018/04/26/3934.pdf).

${ }^{86}$ Cobo, Rosa. (2019) La cuarta ola feminista y la violencia sexual. Revista Interuniversitaria de cultura Paradigma, pp. $134-138$ (p. 134).

${ }^{87}$ Idem op. cit. pp. 134-138 (p. 134).

${ }^{88}$ Espinosa, Ángeles. (8/3/2018). Las feministas iraníes convocan una manifestación el 8M a pesar del veto. El País. Recuperado de https://elpais.com/internacional/2018/03/07/actualidad/1520437481_312006.html.
} 
comparecer ante el tribunal porque le fue negado su derecho a elegir abogado ${ }^{89}$. En la actualidad, Nasrín Sotudé se encuentra encarcelada en la prisión de Evin de Teherán (Irán).

El Código penal de Irán, en concreto, su artículo 638, condena con penas de prisión y multa a las mujeres que aparezcan en los lugares públicos y carreteras sin usar un hijad ${ }^{90}$.

2) Como segundo indicador de la existencia de una Cuarta Ola feminista, se puede destacar el siguiente hecho: En el núcleo del patriarcado, se encuentra el capitalismo neoliberal que justifica la institución de la prostitución y los vientres de alquiler. Analizando los posibles indicadores de la existencia de la Cuarta Ola feminista, Rosa Cobo, señala: "Este movimiento que nos ha desbordado ha sido posible porque la mayoría del movimiento feminista entiende que el capitalismo neoliberal en este momento histórico articula y vehicula algunas demandas patriarcales fundamentales. La capacidad del capitalismo para convertir en un negocio internacional la industria del sexo o los vientres de alquiler explica el interés capitalista en la opresión de las mujeres. La plusvalía sexual es hoy tan imprescindible para el nuevo capitalismo como para los patriarcados contemporáneos"91.

La lucha contra la violencia sexual en la Cuarta Ola del feminismo, "ha de leerse también en el combate contra la prostitución -que ha crecido exponencialmente de la mano de la globalización y la trata- y los vientres de alquiler"92.

El primer instrumento que considera como Violencia de Género: La prostitución y la explotación sexual de la mujer, fue el Convenio del Consejo de Europa sobre prevención y lucha contra la violencia contra las mujeres y la violencia doméstica, de 11 de Mayo de 2011 también conocido, como el Convenio de Estambul, vinculante para España desde el 10 de Abril de 2014, año en el que España lo ratifica ${ }^{93}$ y se compromete a luchar contra todas las formas de violencia contra la mujer que recoge el artículo 3.a) del Convenio de Estambul:

"Por violencia contra la mujer se deberá entender una violación de los derechos humanos y una forma de discriminación contra las mujeres, y se designarán todos los actos de violencia basados en el género que implican o pueden implicar para las mujeres daños o sufrimientos de naturaleza física, sexual, psicológica o económica, incluidas las amenazas de realizar dichos actos, la coacción o la privación arbitraria de libertad, en la vida pública o privada".

\footnotetext{
${ }^{89}$ Europa Press. (11/03/2019). Condenada en Irán a 38 años de cárcel y casi 150 latigazos la destacada abogada pro Derechos Humanos Nasrín Sotudé. Recuperado de https://www.europapress.es/internacional/noticia-condenadairan-38-anos-carcel-casi-150-latigazos-destacada-abogada-pro-ddhh-nasrin-sotude-20190311155758.html.

${ }^{90}$ Código Penal Islámico de la República Islámica de Irán. Libro quinto (18 de julio de 2013). Centro de Documentación de Derechos Humanos de Irán (IHRDC).

${ }^{91}$ Cobo, Rosa. (2019). La cuarta ola feminista y la violencia sexual. Revista Interuniversitaria de cultura Paradigma, pp. 134-138 (p. 137).

${ }_{92}$ La Vanguardia. (11/11/2018). El feminismo se sube a la cuarta ola. Recuperado de https://www.lavanguardia. com/vida/20181111/452836533674/feminismo-bases-movimiento-espana-cuarta-ola.html.

${ }^{93}$ Aguilar, Encarnación. (2019). Prostitución: impugnación del sindicato de "trabajadoras sexuales", denominado bajo las siglas Otras. Revista General del Derecho del Trabajo y la Seguridad Social, no 52, Marzo, pp. 221-256.
} 
En España, la Ley 1/2004, de 28 de Diciembre, de Medidas de Protección Integral contra la Violencia de Género (LOMPIVG), en su artículo 1.1, contempla únicamente la violencia contra la mujer que se produce por su pareja o expareja sentimental; violencia doméstica, una de las formas en que se expresa la Violencia de Género: "La presente Ley tiene por objeto actuar contra la violencia que, como manifestación de la discriminación, la situación de desigualdad y las relaciones de poder de los hombres sobre las mujeres, se ejerce sobre éstas por parte de quienes sean o hayan sido sus cónyuges o de quienes estén o hayan estado ligados a ellas por relaciones similares de afectividad, aun sin convivencia”. Sin embargo, en su Preámbulo, hace especial hincapié: "La violencia de género no es un problema que afecte al ámbito privado. Al contrario, se manifiesta como el símbolo más brutal de la desigualdad existente en nuestra sociedad. Se trata de una violencia que se dirige sobre las mujeres por el hecho mismo de serlo, por ser consideradas, por sus agresores, carentes de los derechos mínimos de libertad, respeto y capacidad de decisión".

El Pacto de Estado contra la Violencia de Género aprobado el 28 de Septiembre de 2017 contempla una revisión legal de la Ley 1/2004, de 28 de Diciembre, LOMPIVG, para que abarque todas las formas en que se expresa la violencia contra la mujer; Violencia de Género, contempladas en el artículo 3. a) del Convenio de Estambul de 11 de Mayo de 2011.

\section{Conclusiones}

La Historia de las mujeres ha sido una larga y constante lucha por la conquista de espacios, visibilidad, derechos y dignidad.

Las tres palabras que definieron la Revolución francesa de 1789, "Libertad, Igualdad y Fraternidad", se dirigieron solo a la mitad de la Humanidad, los Hombres; cuando en la Declaración de los Derechos del Hombre y del Ciudadano de 1789 escribieron hombres, "no querían decir ser humano o persona, se referían exclusivamente a los varones. Ninguno de los derechos fue reconocido para las mujeres"94.

El movimiento feminista surge en la Revolución francesa como un movimiento de lucha por los derechos de la mujer y la igualdad real y efectiva entre hombres y mujeres. El feminismo es un movimiento que se basa en la justicia:

El feminismo es una teoría y práctica política articulada por mujeres que tras analizar la realidad en que viven, toman conciencia de las discriminaciones que sufren por la única razón de ser mujeres y deciden organizarse para acabar con ellas, para cambiar la sociedad. (...) El feminismo se articula como filosofía política y, al mismo tiempo, como movimiento social ${ }^{95}$.

\footnotetext{
${ }^{94}$ Varela, Nuria. (2018). Feminismo para principiantes. Barcelona: Penguin Random House Grupo Editorial, S. A. U.,

${ }^{95}$ Varela, Nuria. (2018). Feminismo para principiantes. Barcelona: Penguin Random House Grupo Editorial, S. A. U.,
} p. 28. p. 14. 
Las primeras reivindicaciones feministas se recogieron en los conocidos como Cuadernos de Queja redactados en 1789.

Los objetivos y reivindicaciones más importantes de la Primera y Segunda Ola del feminismo que mujeres y hombres feministas consiguieron gradualmente, fueron: El derecho al voto, el derecho a la educación, el derecho a acceder a estudios superiores, el derecho a ejercer todas las profesiones, el derecho a compartir la mujer la patria potestad de los hijos, el derecho a ganar el mismo salario que un hombre en la realización de idéntico trabajo.

La Tercera Ola feminista se puede sintetizar en una frase que surge de la mano de la feminista Kate Millett y su obra La política sexual: "Lo personal es político". Millett, dio visibilidad y denunció, la Violencia de Género que sufrían las mujeres en sus hogares: "Problemas tan enraizados y silenciados en la sociedad que aún hoy no se han solucionado como la violencia de género, fueron puestos encima de la mesa (...) Si lo personal es político, las leyes no se pueden quedar a la puerta de la casa"96.

La existencia de la Cuarta Ola feminista se justifica principalmente en el hecho de que el movimiento feminista se ha hecho global. Se han organizado y celebrado manifestaciones feministas en lugares especialmente discriminatorios y opresivos para la mujer como Mosul, Bagdad, Turquía, Arabia Saudita e Irán. Los objetivos y reivindicaciones que identifican a la Cuarta Ola feminista son esencialmente: La lucha contra todas las formas de violencia hacia la mujer, incluida la violencia sexual y prostitución y, la consecución de la paridad entre el hombre y la mujer en todos los ámbitos.

Para finalizar, me acojo a las palabras de la feminista Gerda Lerner en su obra $L a$ creación del patriarcado, cuando destaca: "El sistema del patriarcado es una costumbre histórica; tuvo un comienzo y tendrá un final. Parece que su época ya toca fin"97. Para ello han luchado y siguen luchando mujeres y hombres feministas. Sólo así se podrá hablar de igualdad real y efectiva y, de respecto a la dignidad de las mujeres.

\section{Bibliografía}

AGUILAR, ENCARNACIÓN. (2019). Prostitución: impugnación del sindicato de "trabajadoras sexuales", denominado bajo las siglas Otras. Revista General del Derecho del Trabajo y la Seguridad Social, 52, Marzo.

AMORÓS, CELIA. (1995). Tiempo de feminismo: Sobre feminismo, proyecto ilustrado y postmodernidad. Madrid, España: Cátedra.

AMORÓS, CELIA. (Dir.). (1995). Feminismos, 10 palabras clave sobre mujer. Navarra, España: Verbo Divino.

\footnotetext{
${ }^{96}$ Ibidem op. cit. p. 106.

${ }^{97}$ Lerner, Gerda. (1986). La creación del patriarcado. Barcelona: Editorial Crítica, S.A., p. 330.
} 
AMORÓS, CELIA., DE MIGUEL, ANA. (Eds.). (2005). Teoría feminista: De la Ilustración a la globalización. Del feminismo liberal a la posmodernidad. Madrid, España: Minerva Ediciones, S.L.

BARRY, KATHELEEN. (1988). Esclavitud sexual de la mujer. Barcelona, España: LaSal, D.L. BARRY, KATHELEEN. (2005). Teoría del feminismo radical: Política de explotación sexual. En Celia. Amorós., Ana. De miguel. (Eds.) Teoría feminista: De la Ilustración a la globalización. Del feminismo liberal a la posmodernidad (pp. 188-210). Madrid, España: Minerva Ediciones, S.L.

BEAUVOIR, SIMONE DE (1982). El segundo sexo II. La experiencia vivida. Buenos aires, Argentina: Ediciones Siglo Veinte.

COBO, ROSA. (2019). La cuarta ola feminista y la violencia sexual. Revista Interuniversitaria de cultura Paradigma.

FRIEDAN, BETTY. (2009). La mística de la feminidad. Madrid: Cátedra.

BLANCO, OLIVA. (2000). Olimpia de Gouges (1748-1793). Madrid, España: Ediciones del Orto. CABRERA, MARÍA ISABEL. (1988). Las mujeres que lucharon solas: Concepción Arenal y Emilia Pardo Bazán. En Pilar. Folguera. (coord.), El feminismo en España: Dos siglos de historia. Madrid, España: Fundación Pablo Iglesias.

CAMPOAMOR, CLARA. (2001). Mi pecado mortal. El voto femenino y yo. Sevilla, España: Instituto Andaluz de la Mujer.

COBO, ROSA. (1994). El discurso de la igualdad en el pensamiento de Poulain de la Barre. En Celia. Amorós. (coord.), Historia de la Teoría Feminista. Madrid, España: Instituto de investigaciones feministas.

COBO, ROSA. (1994). La construcción social de la mujer en Mary Wollstonecraf. En Celia. Amorós. (coord.), Historia de la teoría feminista. Madrid, España: Instituto de Investigaciones Feministas.

DE MIGUEL, ANA. (2000). Los feminismos. Recuperado de http://acoca2.blogs.uv.es/files/2013/12/Los-feminismos.pdf.

DE MIGUEL, ANA. (2000). Los feminismos. En Celia. Amorós. (Dir),10 palabras clave sobre mujer. Pamplona, España: Editorial Verbo Divino.

DE MIGUEL, ANA. (2005). La construcción de un marco feminista de interpretación: La violencia de género. Cuadernos de Trabajo Social, 18, 231-248.

DE MIGUEL, ANA. (2005). John Stuart Mill y Harriett Taylor Mill: Desarticulando la ideología patriarcal. Recuperado de http://acoca2.blogs.uv.es/files/2013/11/6-Mill-CTF1.pdf.

DE MIGUEL, ANA. (2011). Los feminismos a través de la historia. Recuperado de https:// web.ua.es/es/sedealicante/documentos/programa-de-actividades/2018-2019/ los-feminismos-a-traves-de-la-historia.pdf.

DE PIZÁN, CRISTINA. (2001). La ciudad de las Damas, traducción de Marie-José Lemarchand, Madrid, España: Siruela.

DE ZAYAS, MARÍA. (1989). Tres novelas amorosas y tres desengaños amorosos. Madrid: Editorial Castalia, S.A.

DOMINGO, CARMEN. (2004). Con voz y voto. Las mujeres y la política en España (19311945). Barcelona, España: Lumen. 
ESPINOSA, ÁNGELES. (8/3/2018). Las feministas iraníes convocan una manifestación el 8Ma pesar del veto. El País. Recuperado de https://elpais.com/internacional/2018/03/07/ actualidad/1520437481_312006.html.

FAOAGA, CONCHA. (1999). 1898-1999. Un siglo avanzando hacia la igualdad de la mujer. Madrid, España: Dirección General de la Mujer.

FRIEDAN, BETTY. (1983). La segunda fase. Barcelona, España: Plaza y Janés.

FRIEDAN, BETTY. (2003). Mi vida hasta ahora, Madrid, España: Cátedra.

GIL, JUANA MARÍA. (2006). John Stuart Mill y la violencia de género: Las trampas de la educación diferencial. Recuperado de https://www.boe.es/publicaciones/anuarios_derecho/abrir_pdf.php?id=ANU-F-2006-10006100084_ANUARIO_DE_ FILOSOF\%CDA_DEL_DERECHO_John_Stuart_Mill_y_la_violencia_de_g\%E9nero:_las_ trampas_de_la_educaci\%F3n_diferencial.

IRIGARAY, LUCE. (1992). Yo, tu, nosotras. Madrid: Cátedra, D.L.

LARAÑA, ENRIQUE. (1999). La construcción de los movimientos sociales. Madrid: Alianza.

LARAÑA, ENRIQUE., GUSFIELD, JOSEPH. (1994). Los nuevos movimientos sociales. De la ideología a la identidad. Madrid: Centro de Investigaciones Sociológicas (CIS).

LERNER, GERDA. (1986). La creación del patriarcado. Barcelona: Editorial Crítica, S. A.

LÓPEZ, TERESA. (1999). Simone de Beauvoir (1908-1986). Madrid, España: Ediciones del Orto.

LÓPEZ, TERESA. (2005). El feminismo existencialista de Simone de Beauvoir. En Celia. Amorós., Ana. De Miguel. (Eds.),Teoría feminista: De la Ilustración a la globalización (pp. 338-355). Madrid, España: Minerva Ediciones, S.L.

LEÓN, STELLA. (2010). François Poulain de la Barre: Feminismo y Modernidad. Astrolabio: Revista Internacional de Filosofía, 11, 257-270.

LEÓN, STELLA. (2011). François Poulain de la Barre: Filósofo feminista y cartesiano sui generis. Éndoxa: Series filosóficas, 27, 37-57.

LOPETEGUI, ARANTXA., COLMENERO, JAVI. (15/02/2019). La cuarta ola feminista un "movimiento de masas" se reivindica en Tolosa. Noticias de Gipuzkoa. Recuperado de http://www.noticiasgipuzkoa.eus/2019/02/15/sociedad/la-cuarta-ola-feministaun-movimiento-de-masas-se-reivindica-en-Tolosa.

MORA, MIGUEL. (13/02/2011). Un millón de mujeres dicen no a Berlusconi y al machismo. El País Recuperado de https://elpais.com/internacional/2011/02/13/actualidad/1297551605_850215.html.

MILLETT, KATE. (1995). La política sexual. Madrid: Cátedra, S.A.

MIYARES, ALICIA. (1999). 1848: El manifiesto de Seneca Falls. Revista Leviatán, 75, 135-158. MIYARES, ALICIA (11/03/2018) La cuarta ola del feminismo, su Agenda. Tribuna Feminista. Recuperado de https://tribunafeminista.elplural.com/2018/03/la-cuarta-oladel-feminismo-su-agenda/.

MURARO, LUISA. (1994). El orden simbólico de la madre. Madrid: Editorial Horas y horas. NASH, MARY. (2004). Mujeres en el mundo. Historia, retos y movimientos. Madrid, España: Alianza. 
ORDÓÑEZ, ANA LUISA. (2006). Feminismo y prostitución. Fundamentos del debate actualmente en España. Oviedo, España: Trabe.

PERONA, ÁNGELES. (2005). El feminismo liberal estadounidense de posguerra.En Celia. Amorós., Ana. De Miguel. (eds.), Teoría feminista: de la Ilustración a la globalización. Del feminismo liberal a la posmodernidad (pp. 15-34). Madrid: Minerva Ediciones, S.L. POSADA, LUISA. (1999). Feminismo, igualdad y discurso contemporáneo (a 150 años de Séneca Falls). En Concha. Fagoaga. (coord.), 1898-1998. Un siglo avanzando hacia la igualdad de las mujeres (pp. 294-297). Madrid, España: Dirección General de la Mujer.

POSADA, LUISA. (2005). La diferencia sexual como diferencia esencial: Sobre Luce Irigaray. En Celia. Amorós., Ana. De Miguel. (Eds.), Teoría feminista: de la Ilustración a la globalización. Del feminismo liberal a la posmodernidad. Madrid: Minerva Ediciones, S.L. RAMÍREZ, MARÍA DOLORES., GONZÁLEZ, JUAN., CERRATO, DANIELE., y MARTÍN, MILAGRO. (2011). La querella de las mujeres de España a Latinoamérica. Vol. 2. Sevilla, España: Arcibel.

REQUENA, ANA., BORRAZ, MARTA. (4/10/2018). El movimiento \#MeToo, corazón de una nueva ola feminista que pone el foco en la violencia sexual. El Diario. Recuperado de https://www.eldiario.es/sociedad/movimiento-MeToo-corazon-feminista-violencia_0_821368506.html).

RODRÍGUEZ, MARÍA EUGENIA., LOURDES, LUCÍA., BARBA, ANA., y BRAVO, PALOMA. ¿Una nueva ola feminista? Espacio Público. Recuperado de http://www.espacio-publico. com/el-despertar-del-nuevo-feminismo.

RUBIALES, AMPARO. (3/04/2018). La cuarta ola feminista. Huffington Post. Recuperado de https://www.huffingtonpost.es/amparo-rubiales/la-cuarta-ola-feminista_a_23 401645/.

SENDÓN, VICTORIA. (2002). Marcar las diferencias, Discursos feministas ante un nuevo siglo. Barcelona, España: Icaria.

STOLLER, ROBERT. (1968). Sex and gender. New York: Science House.

STUART MILL, JOHN., TAYLOR MILL, HARRIET. (1973). Ensayos sobre la igualdad sexual. Barcelona, España: Península.

STUART MILL, JOHN., TAYLOR MILL, HARRIET. (2001).Ensayos sobre igualdad sexual. Madrid, España: Ediciones Cátedra.

STUART MILL, JOHN. (1965). Sobre la libertad. México: Editorial Diana S.A.

TRISTÁN, FLORA. (2003). Feminismo y socialismo. Antología. Madrid, España: Los libros de la Catarata.

TRISTÁN, FLORA. (2005). La Unión Obrera. Barcelona: De Barris.

THOMPSON, WILLIAM., WHEELER, ANNA. (2000).La demanda de la mitad de la raza humana, las mujeres, contra la pretensión de la otra mitad los hombres de mantenerlas en la esclavitud política y, en consecuencia, civil y doméstica. Granada, España: Editorial Comares.

VALCÁRCEL, AMELIA. (2001). La memoria colectiva y los retos del feminismo. Recuperado de https://repositorio.cepal.org/bitstream/handle/11362/5877/S01030209_es.pdf 
VARELA, NURIA. (2018). Feminismo para principiantes. Barcelona: Penguin Random House Grupo Editorial, S. A. U.

VARELA, NURIA. (26/01/2013). Christine de Pizán y “La ciudad de las damas”. Recuperado de http://nuriavarela.com/christine-de-pizan-y-la-ciudad-de-las-damas/.

WOLLSTONECRAF, MARY. (2000). Vindicación de los derechos de la mujer. Madrid, España: Cátedra. 